\title{
Effect of the loading of organomodified clays on the thermal and mechanical properties of a model dental resin
}

\author{
Marina Martins Terrin ${ }^{a}$, Alessandra Leves Poli ${ }^{a}$, Marco Antonio Horn Jra, \\ Miguel Guillermo Neumann ${ }^{a}$, Eder Tadeu Gomes Cavalheiro ${ }^{a}$, Ivo Carlos Correa ${ }^{b}$, \\ Carla Cristina Schmitt * \\ anstituto de Química de São Carlos - IQSC, Universidade de São Paulo - USP, \\ Av. Trab. São-Carlense, 400, CEP 13560-970, São Carlos, SP, Brazil. \\ ${ }^{b}$ Departamento de Prótese e Materiais Dentários, Faculdade de Odontologia, \\ Universidade Federal do Rio de Janeiro - UFRJ, Av. Carlos Chagas Filho 373, \\ CEP 21941-902, Rio de Janeiro, RJ, Brazil.
}

Received: March 18, 2015; Revised: October 16, 2015; Accepted: November 17, 2015

\begin{abstract}
Experimental dental resins composed of triethyleneglycol dimethacrylate, urethane dimethacrylate, ethoxylated bisphenol-A-dimethacrylate and bisphenol A glycidyl methacrylate containing an organoclay as filler were prepared by photopolymerization. The addition of organoclay fillers results in slower polymerization rates $\left(0.59\right.$ and $0.24 \mathrm{~mol} \mathrm{~L}^{-1} \mathrm{~min}^{-1}$, for the formulations without and with $15 \%$ of organoclay, respectively) and lower degrees of conversion ( 0.50 and 0.35 for the formulations without and with $15 \%$ of organoclay), as determined by photocalorimetry. The influence of the organoclay on the thermal and mechanical properties of the resins was evaluated using thermogravimetric analysis (TGA) and dynamic mechanical analysis (DMA) techniques. The ( $\tan \delta$ ) and $E^{\prime}$ curves indicate the formation of more rigid materials and the damping curve data indicates more homogeneous materials. An increase of storage modulus, $E$,' was observed for composites with the higher organoclay filler contents. These effects are due to the higher viscosity of the systems with organoclay, resulting in a lower mobility of the radicals during the propagation step of polymerization, as well as to the scattering of the incident photopolymerizing radiation, which lowers the amount of initiation centres.
\end{abstract}

Keywords: Dental materials; Dental resins; Nanocomposites; Thermal analysis; Organoclay

\section{Introduction}

Polymeric composites containing inorganic fillers cured by visible light are commonly used as filling materials in dental restorations. Usually the composition of these materials contains $75-85 \%(\mathrm{w} / \mathrm{w})$ of inorganic material and $15-25 \%$ of a polymeric matrix based on dimethacrylate monomers. ${ }^{1}$ The shrinkage of the polymeric material, ${ }^{1,2}$ which occurs during the polymerization process, may result in a loss of resistance and formation of creases. Degradation of the organic matrix is enhanced at these sites, as well as undesired sorption of oral fluids. The inorganic fillers, silica or quartz, are added to improve the mechanical properties of the restoration. Strength, hardness, thermal expansion coefficient, wear resistance, sorption processes and polymerization shrinkage are all dependent on the filling and the coupling agents. ${ }^{3,4}$

The use of nanoclays as matrixes in dental resins is based on the exfoliation of clays promoting the clay-polymer interactions at the nanoscale dimensions. ${ }^{5}$ Nanofilled dental resins containing from 1 to $100 \mathrm{~nm}$-size particles have been developed in the search for materials with low

*e-mail: carla@iqsc.usp.br polymerization shrinkage, and better mechanical, optical and polishing characteristics. The size of the particles and their composition determine the classification of the dental composite resins as microfilled, nanofilled and nanohybrid, each one of them characterizing particular physical, mechanical and aesthetic properties. ${ }^{6,7}$

Small amounts of nanoclays have been shown to improve mechanical, thermal and barrier properties due to the larger interface area promoted by the nanoparticles of the suspended filler. ${ }^{8-10}$

Organoclays, that are clays where the $\mathrm{Na}^{+}$counterions were exchanged by a cationic detergent, were used in this work. Their surfactant character allows a better interaction with the monomers than non modified clays. Therefore, these new type of fillers might present better properties for their use in dental materials. The effect of different loadings of organoclays derived from montmorillonite clays on the mechanical properties, as well as on the photopolymerization kinetics of an experimental dental resin were evaluated using thermoanalytical and mechanical techniques. These studies may contribute to develop new fillers for dental materials. 


\section{Materials and methods}

\subsection{Materials}

The montmorillonite clay $\left(\mathrm{SWy}-1 / \mathrm{Na}^{+}\right)$used in the experiments was obtained from the Source Clays Repository of the Clay Minerals Society, University of Missouri, Columbia, MI. The monomers used were triethyleneglycol dimethacrylate (TEGDMA), urethane dimethacrylate (UDMA), ethoxylated bisphenol-A-dimethacrylate (Bis-EMA, $\mathrm{M}_{\mathrm{n}}$ 1700) and bisphenol A glycidyl methacrylate (Bis-GMA). Camphorquinone (CQ) and ethyl 4-dimethylaminobenzoate (EDB) were use as photoinitiator and co-initiator, respectively. All the monomers, CQ and EDB were from Aldrich Chemical Co., Milwaukee, WI. Hexyltrimethylammonium bromide (C16, Sigma) was used as modifying agent in the preparation of the organoclay.

\subsection{Procedure for obtaining the organoclay}

The SWy-1 clay was purified and converted to the organoclay in order to increase its hydrophobic character and better interact with the monomers. The procedure involved cation exchange between the sodium counterion of the SWy-1/Na ${ }^{+}$and the $\mathrm{C} 16$ cationic detergent, according to a previously described methodology. ${ }^{9}$ The incorporation of the $\mathrm{C} 16$ chain was confirmed by XRD measurements that show that the interlamellar spacing of the clay changes from $12.0 \AA$ for the pure clay before cation exchange to around $17 \AA$ for the organoclays (see the corresponding Figure in the Supplementary Material).

\subsection{Preparation of the specimens}

A model dental resin was prepared by mixing 4 monomers, in the same proportion as the formulation of the commercial light-curing resin Filtek Z250 (3M ESPE, St. Paul, MN, USA), i.e., TEGDMA 7\%, UDMA, 29\%, Bis-EMA, 29\%, Bis-GMA, 34\% w/w. Different amounts of organoclay were added to the mixture: $0,0.5,2.0,5.0,7.5,10.0$, and $15 \%$. Finally, CQ and EDB $(0.5 \% \mathrm{w} / \mathrm{w}$ of each) were added to prompt the photopolymerization. The monomers, along with the photoinitiation system and the organoclay, were homogenized in a vacuum mixer (Vacumixer, Polidental). The samples were stored in opaque recipients at $4{ }^{\circ} \mathrm{C}$.

The samples were placed in Teflon moulds $(35.0 \times 5.0 \times 1.0 \mathrm{~mm})$ and cured for 90 seconds, using a $600 \mathrm{~mW} . \mathrm{cm}^{-2}$ power LED lamp (UltraBlue IS, DMC Instr.) with emission cantered at a $470 \mathrm{~nm}$ (blue light) placed at $3 \mathrm{~mm}$. The cured specimens were removed from the moulds and submitted to mechanical and thermal analyses.

\subsection{Dynamic Mechanical Analysis - DMA}

The mechanical properties of the samples were determined (DMA, Q800, TA Instruments, New Castle, DE, USA) in the temperature range of $-50{ }^{\circ} \mathrm{C}$ to $165^{\circ} \mathrm{C}$, at a heating rate of $3{ }^{\circ} \mathrm{C} / \mathrm{min}$. The effect of chewing was simulated by using a frequency of $1 \mathrm{~Hz}$. Liquid nitrogen was used to cool the sample and create an inert atmosphere for analysis. Storage moduli ( $\left.E^{\prime}\right)$ and loss tangents (tan $\delta$, the rate between the storage and loss moduli) were obtained as a function of temperature. Glass transition temperatures $\left(T_{g}\right)$ were determined from the maximum of the loss tangent versus temperature curves.

\subsection{Thermogravimetry (TGA)}

Samples of about $6 \mathrm{mg}$ were put in an open alumina pan and analyzed on a Simultaneous Thermogravimetric Analyser (SDT- Q600, TA Instruments, New Castle, DE, USA), with an alumina clamp holding the sample in an air atmosphere at a flowing rate of $100 \mathrm{~mL} / \mathrm{min}$. The temperature was varied between 20 and $1000{ }^{\circ} \mathrm{C}$ at a heating rate of $10^{\circ} \mathrm{C} / \mathrm{min}$.

\subsection{Photocalorimetry (PCA)}

The photopolymerization process was determined by photo-DSC, using a differential scanning calorimeter in photocalorimetric mode (Photo-DSC Q-2000, TA Instruments, New Castle, DE, USA), using an accessory with a mercury vapour lamp as irradiation source (OnmiCure Series 2000). For kinetic and conversion analyses, $40 \mathrm{mg}$ of the monomer mixture with different organoclay loadings were put on an alumina pan under $\mathrm{N}_{2}$ atmosphere at a flowing rate of $50 \mathrm{~mL} / \mathrm{min}$. The light source used had an irradiation power of $100 \mathrm{~mW} \mathrm{~cm}^{-2}$. The temperature was kept constant at $36.5^{\circ} \mathrm{C}$ using a TA RCS refrigeration system.

The degree of conversion $(\mathrm{C} \%)$ was determined using Equation 1:

$C \%=100 \times \frac{\Delta H_{t}}{\Delta H_{0}^{\text {theor }}}$

where $\Delta \mathrm{H}_{t}$ is the reaction heat evolved at time $t$ and $\Delta H_{0}^{\text {theor }}$ is the theoretical heat for the total conversion of the monomers present in the sample. In this work, the theoretical enthalpy for the conversion of double bonds was assumed to be $60 \mathrm{~kJ} \mathrm{~mol}^{-1}$, similar to that reported previously, ${ }^{10,11}$ thus, for bifunctional monomers the enthalpy for the system should be $120 \mathrm{~kJ} \mathrm{~mol}^{-1}$.

Polymerization rates $\left(R_{p}\right)$ were calculated according to Equation 2 assuming that they are proportional to the heat flow $(d H / d t)^{12}$

$$
R_{p}=\frac{d H / d t}{\Delta H_{0}^{\text {theor }}}
$$

\section{Results and Discussion}

\subsection{Dynamical mechanical analysis (DMA)}

Fig. 1 shows the $(\tan \delta)$ vs. temperature curves for the composites containing different clay loadings. The presence of various peaks and their widths are parameters that can be used to evaluate the heterogeneity of the polymer due to the mixture of regions with different crosslinking degrees. Two broad peaks can be observed around 45 and $105^{\circ} \mathrm{C}$, which suggest a heterogeneous polymeric network. ${ }^{13,14}$ However, it can be seen that for the higher clay loadings (over 5\%), the lower temperature peak tends to disappear, indicating that the heterogeneity of the resin is being reduced. Thus, the presence of the clay seems to turn the resins more homogeneous favouring the formation of crosslinked domains, and lowering the mobility of the polymeric chains.

It is worthwhile to note that, whereas the peak at $45^{\circ} \mathrm{C}$ decreases, the second peak practically does not change its intensity. This peak is associated to the glass transition temperature of the resin, $T_{g}$. Its value is $106{ }^{\circ} \mathrm{C}$ for the resin without clay. When clay is added the values decrease 


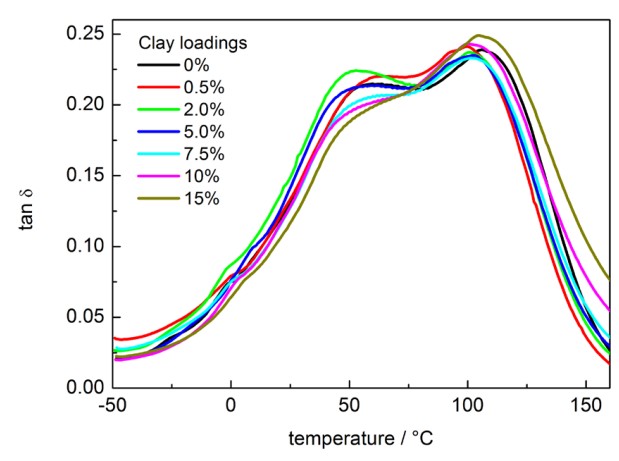

Figure 1. Dependence of $(\tan \delta)$ with temperature for the composites.

slightly, to around $102{ }^{\circ} \mathrm{C}$, returning to practically $106^{\circ} \mathrm{C}$ at the higher clay loading used (15\%).

Fig. 2 shows the temperature dependence of the storage modulus $\left(E^{\prime}\right)$ for the composites. Results shown in the inset suggest that at low temperatures $E^{\prime}$ decreases with the clay content whereas at room temperature and above $\left(>25^{\circ} \mathrm{C}\right)$ the tendency is opposite, as also suggested by the $(\tan \delta)$ behaviour. This means that the presence of the organoclay leads to more rigid composites and that the organoclay filler limits the mobility of the polymeric chains at the clay-polymer interface, promoting higher resistance of the material against deformation. ${ }^{14,15}$ This is a desirable condition for dental composites, that should have intermediate properties for hardness and deforming capacity, approaching the behaviour of the material to the prediction of the Hooke's Law. ${ }^{15}$

\subsection{Thermogravimetry (TGA)}

Figs. 3A and 3B show the TGA and DTG curves for the dental composites. It can be seen in Fig. 3B that the thermal degradation occurs in three steps. The first one between 300 and $380^{\circ} \mathrm{C}$, the second from 380 to $460{ }^{\circ} \mathrm{C}$, and a final step from 470 to $610^{\circ} \mathrm{C}$. For all samples (with and without added organoclay) there is an initial small mass loss of nearly $1 \%$ between 100 and $250{ }^{\circ} \mathrm{C}$ that may be assigned to the loss of water and unpolymerized monomers.

The thermal degradation of other methacrylate polymers, such as poly(methyl methacrylate), PMMA, also involves three main steps: ${ }^{16,17}$

a) decomposition initiated at weak bonds formed during the head-to-head termination reactions of the polymerization process; ${ }^{18}$

b) decomposition of PMMA initiated at vinylidene end groups, ${ }^{19}$

c) random polymer main chain scissions at higher temperatures.

Although the organoclay shows a decomposition with peaks around 330 and $600{ }^{\circ} \mathrm{C},{ }^{20}$ its amount is negligible compared with the decomposition of the polymer. The residue remaining after heating over $600{ }^{\circ} \mathrm{C}$ corresponds basically

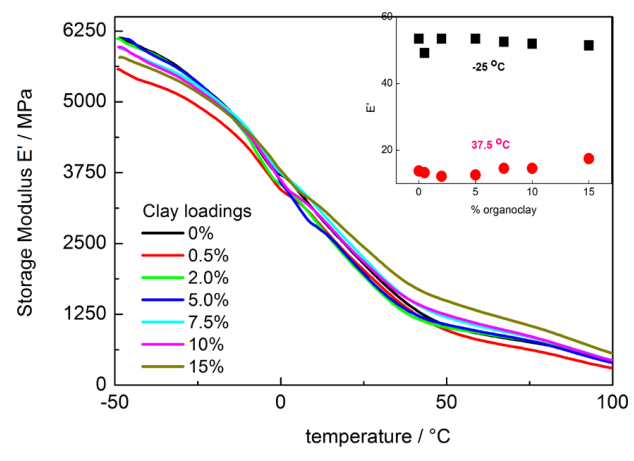

Figure 2. Temperature dependence of the storage modulus $\left(E^{\prime}\right)$ for the composites. Inset: loading dependence at -25 and $37.5^{\circ} \mathrm{C}$.
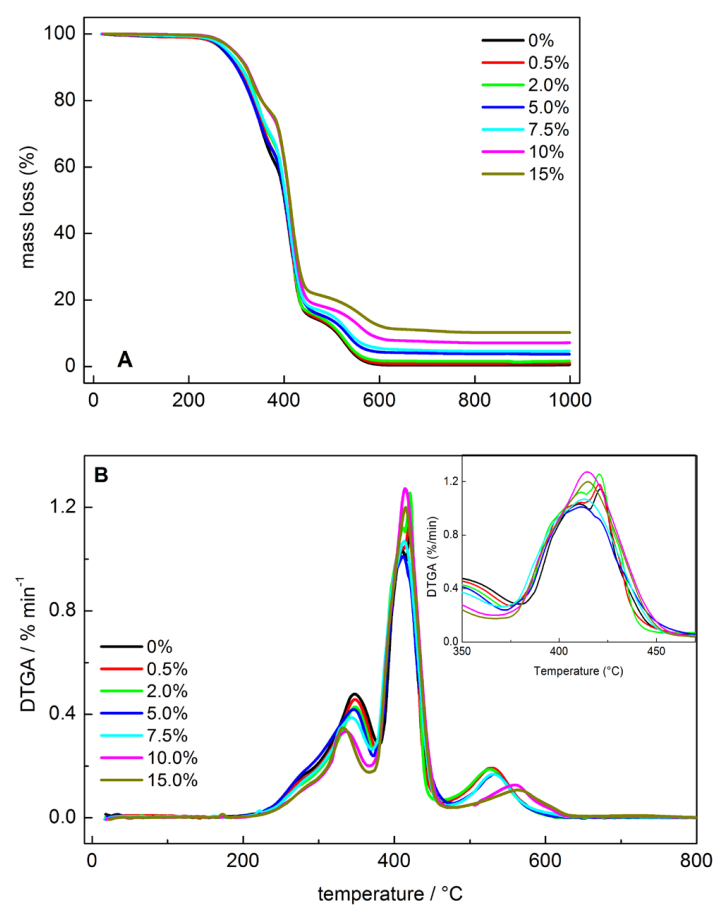

Figure 3. (A) TGA and (B) DTGA curves for the resins. Inset: Blow-up of the $350-400{ }^{\circ} \mathrm{C}$ region.

to the inorganic leftover of the clay, and is proportional to amount of organoclay in the resins.

It can be noticed from the inset in Fig. 3 that for the thermal degradation of the polymers with low clay content the peak in the region of $400^{\circ} \mathrm{C}$ appears is split into two components at $\sim 410$ and $420{ }^{\circ} \mathrm{C}$, suggesting that the polymerization process is not completely homogeneous. At higher clay concentrations, only one peak remains, indicating that the presence of the clay might avoid the formation of the low energy bonds during the polymerization process. Clays seem to be favouring the homogenization of the systems acting like a thermal stabilizer. For all compositions, a fourth degradation step is observed between 530 and $560^{\circ} \mathrm{C}$, attributed to main polymer chain scissions. 


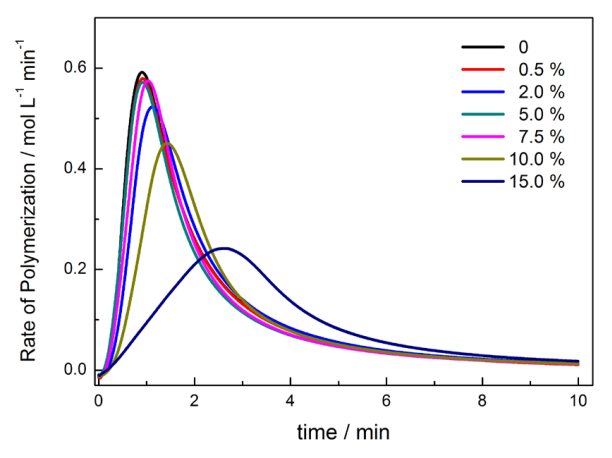

Figure 4. Polymerization rates at different clay loadings.

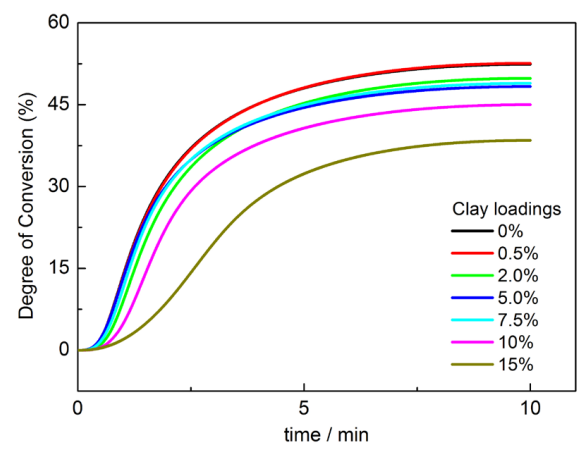

Figure 5. Degrees of conversion of the monomer.

\subsection{Photocalorimetry (PCA)}

Figures 4 and 5 and Table 1 show the polymerization rates and degrees of conversion of the monomers, respectively. It can be seen that the increase of the organoclay loading promotes the decrease of the polymerization rates, as well as lower conversions.

The presence of the organoclay particles with $\mathrm{C} 16$ attached chains will form micelle like microheterogeneous domains in which monomers may disperse before polymerization. This leads to the formation of smaller clay/polymer nanoparticles, conferring a more homogenous and crosslinked final polymerized resin. ${ }^{10}$

Achilias et al,. studied the thermal decomposition of resins with no clay containing only TEGDMA, Bis-EMA, Bis-GMA, and UDMA. ${ }^{21}$ Based on these studies it was proposed that photoinitiated reactions by free radicals start at multiple sites during irradiation, thus resulting in non-homogeneous polymerization. In these initiation sites, microgel areas are formed in which residual monomers and highly crosslinked polymer areas coexist. ${ }^{22}$ As shown in Figs. 4 and 5, the presence

\section{References}

1. Mucci V, Perez J and Vallo CI. Preparation and characterization of light-cured methacrylate/montmorillonite nanocomposites. Polymer International. 2011; 60(2):247-254. http://dx.doi. org/10.1002/pi.2935.
Table 1. Maximum polymerization rates.

\begin{tabular}{cc}
\hline Clay concentration & $\boldsymbol{R}_{p} / \mathbf{~ m o l ~ L}^{-1} \mathbf{~ m i n}^{-1}$ \\
\hline 0 & 0.59 \\
0.5 & 0.58 \\
2 & 0.52 \\
5 & 0.57 \\
7.5 & 0.58 \\
10 & 0.45 \\
15 & 0.24 \\
\hline
\end{tabular}

of organoclay fillers causes slower polymerization rates and lower degrees of conversion. These effects are similar to those observed for the photopolymerization of UDMA/TEGDMA dental resins in the presence of silanized silica fillers. ${ }^{23}$ Due to the brightness of the clays, an additional factor that should be considered to explain the lower polymerization rates is that part of the incident light will be scattered by the filler. ${ }^{23}$

\section{Conclusions}

The use of organoclays as fillers in dental resin composites was tested, and from the results obtained, it seems to be a potential component for improving the properties of these materials. On one side, their inclusion results in slower polymerization rates, which will render more homogeneous fillings, preventing cracks and post restoration pains. TGA and DTG experiments indicate that the polymers obtained from samples with no organoclay addition are non-homogeneous: the $(\tan \delta)$ plot shows two peaks, whereas the addition of $5-15 \%$ decreases significantly the lower temperature peak.

An increase of $E$ ' at higher temperatures was observed in composites containing higher organoclay content, indicating a reinforcement of those composites. The presence of organoclays can limit the mobility of the polymeric chains at the clay-polymer interface indicating higher resistance of the material against deformation, as suggested by the DMA results.

These effects may be due to the increase of the viscosity when the organoclay content is added, promoting lower mobility of radicals during the propagation step of polymerization.

Further studies, mainly form a clinical point of view, will be necessary to ascertain the real conditions under which these new fillers could be used.

\section{Acknowledgments}

The authors would like to thank the LATEQS group for providing the instruments for thermal analysis. MMT thanks CAPES (Brazil) and MAHJ, FAPESP (Brazil) for Graduate Fellowships (2011/2108-5) and financial support by the São Paulo Research Foundation, FAPESP (grant 2012/19656-0) is gratefully acknowledged.

2. Sideridou I, Tserki V and Papanastasiou G. Study of water sorption, solubility and modulus of elasticity of light-cured dimethacrylate-based dental resin. Biomaterials. 2003; 24(4):655665. http://dx.doi.org/10.1016/S0142-9612(02)00380-0.

3. Kenshima S, Grande RH, Singer M and Ballester RY. Effect of thermal cycling and filling technique on leakage of composite resin 
restorations. Journal of Applied Oral Science. 2004; 12(4):307311. http://dx.doi.org/10.1590/S1678-77572004000400010.

4. Saber-Sheikh K, Clarke RL and Braden M. Viscoelastic properties of some soft lining materials. I. Effect of temperature. Biomaterials. 1999; 20(9):817-822. http://dx.doi.org/10.1016/ S0142-9612(98)00236-1.

5. Chin IJ, Thurn-Albrecht T and Kim H. On exfoliation of montmorillonite in epoxy. Polymer. 2001; 42(13):5947-5952. http://dx.doi.org/10.1016/S0032-3861(00)00898-3.

6. Turssi CP, Ferracane JL and Vogel K. Filler features and their effects on wear and degree of conversion of particulate dental resin composites. Biomaterials. 2005; 26(24):4932-4937. http:// dx.doi.org/10.1016/j.biomaterials.2005.01.026.

7. Chen M-H. Update on dental nanocomposites. Journal of Dental Research. 2010; 89(6):549-560.

8. Alexandre M and Dubois P. Polymer-layered silicate nanocomposites: preparation, properties and uses of a new class of materials. Materials Science and Engineering. 2000; 28(1):1-63. http:// dx.doi.org/10.1016/S0927-796X(00)00012-7.

9. Qin H, Zhang S, Liu H, Xie S, Yang M and Shen D. Photooxidative degradation of polypropylene/montmorillonite nanocomposites. Polymer. 2005; 46(9):3146-3149. http:// dx.doi.org/10.1016/j.polymer.2005.01.087.

10. Ray SS, Yamada K, Okamoto M, Fujimoto Y, Ogami A and Ueda K. New polylactide/layered silicate nanocomposites. 5. Designing of materials with desired properties. Polymer. 2003; 44:6633-6646.

11. Neumann MG, Oliveira HP and Cione AP. Energy transfer between aromatic hydrocarbons dissolved in a C18-surfactant layer adsorbed on laponite. Adsorption. 2002; 8(2):141-146.

12. Lukaszczyk J, Janicki B and Frick A. Investigation on synthesis and properties of isosorbide base bis-GMA analogue. Journal of Materials Science. Materials in Medicine. 2012; 23(5):11491155. http://dx.doi.org/10.1007/s10856-012-4594-6.

13. Dickens SH, Stansbury JW, Choi KM and Floyd CJ. Photopolymerization kinetics of methacrylate dental resins. Macromolecules. 2003; 36(16):6043-6053. http://dx.doi. org $/ 10.1021 / \mathrm{ma} 021675 \mathrm{k}$.

14. Jedrzejewska B, Pietrzak M and Paczkowski J. Tetramethylammonium phenyltrialkylborates as co-initiators with novel two-cationic styrylbenzimidazolium dyes in highly efficient, visible light polymerization of acrylate. Journal of Photochemistry and
Photobiology. Part A. Chemistry. 2010; 214(2):276-283. http:// dx.doi.org/10.1016/j.jphotochem.2010.07.012.

15. Li Y, Zhao B, Xie S and Zhang S. Synthesis and properties of poly(methyl methacrylate)/montmorillonite (PMMA/MMT) nanocomposites. Polymer International. 2003; 52(6):892-898. http://dx.doi.org/10.1002/pi.1121.

16. Lakshmi U, Mohanty S, Nayak SK and Ali A. Preparation and characterization of poly(methyl methacrylate)/clay nanocomposites via melt intercalation: effect of organoclay on thermal, mechanical an flammability properties. Materials Science and Engineering A. 2011; 528(12):3943-3951. http:// dx.doi.org/10.1016/j.msea.2011.01.071.

17. Mesquita RV and Geis-Gerstorfer J. Influence of temperature on the visco-elastic properties of direct and indirect dental composite resins. Dental Materials. 2008; 24(5):623-632. http://dx.doi.org/10.1016/j.dental.2007.06.025.

18. Meneghetti $P$ and Qutubuddin S. Synthesis, thermal properties and applications of polymer-clay nanocomposites. Thermochimica Acta. 2006; 442(1-2):74-77. http://dx.doi.org/10.1016/j. tca.2006.01.017.

19. Lerari D, Peeterbroeck S, Benali S, Benaboura A and Dubois P. Use of a new natural clay to produce poly(methyl methacrylate)based nanocomposites. Polymer International. 2009; 59(1):7177. http://dx.doi.org/10.1002/pi.2691.

20. Kashiwagi T, Du FM, Douglas JF, Winey KI, Harris RH and Shields JR. Nanoparticle networks reduce the flammability of polymer nanocomposites. Nature Materials. 2005; 4(12):928933. http://dx.doi.org/10.1038/nmat1502.

21. Achilias DS, Karabela MM and Sideridou ID. Thermal degradation of light-cured dimethacrylate resins. Part I. Isoconversional kinetic analysis. Thermochimica Acta. 2008; 472(1-2):74-83. http://dx.doi.org/10.1016/j.tca.2008.02.004

22. Ganguly S, Dana K and Ghatak S. Thermogravimetric study of n-alkylammonium-intercalated montmorillonites of different cation exchange capacity. Journal of Thermal Analysis and Calorimetry. 2010; 100(1):71-78. http://dx.doi.org/10.1007/ s10973-009-0588-0

23. Tanimoto Y, Hayakawa $\mathrm{T}$ and Nemoto K. Analysis of photopolymerization behavior of UDMA/TEGDMA resin mixture and its composite by differential scanning calorimetry. Journal of Biomedical Materials Research. Part B, Applied Biomaterials. 2005; 72B(2):310-315. 